\title{
JULIUS ZUPITZA.
}

In gleichem lebensalter wie ten Brink, anch im 52. jahre, warde der englischen philologie wiederum einer ihrer vorztglichsen vertreter, Julius Zupitza, entrissen. Während wir in ten Brink vor allem einen feinfthligen trefflichen Literaturhistoriker, wie seine Chancerarbeiten und sein hauptwerk, die Literaturgeschichte Englands, beweisen, besassen, der aber anch anf metrischem und sprachlichem gebiet treffliches leistete, der in seinen vorlesungen einen weiten blick in das geistesleben der Engländer und der romanischen völker eröffnete, verlieren wir in Zupitza einen forscher, der, in Haupts and Mullenhoffs schule herangebildet, der textkritik sich widmete, dem sprachgebrauch der einzelnen dichter nachgieng und bedeutendes in ausgaben von literaturwerken und commentaren zu schriftstellern leistete. Hat Zupitza daher auch keine so grossartig angelegten werke wie ten Brink geschaffen, so beweisen viele gelegentliche bemerkungen in anmerkungen und besprechungen zerstrent, dass ihm die ganze englische literatur sehr zur hand war, die schriften Englands in allen zeiten sehr wol bekannt. Als akademischer lehrer aber war Zupitza noch von grösserer bedeutung als ten Brink. Denn er, ein besserer menschenkenner, wusste die eigenheiten seiner schtuler schneller zu erkennen, ihre vorztige und ihre fehler, und daher sie besser zu bilden und zu erziehen als sein college. Daher erklärt es sich auch, dass schuler von Zupitza an einer reihe von dentschen und englischen hochschulsn unterrichten, während ten Brink durch sein etwas zurttckhaltendes wesen niemals eine schule bildete. Brandl, Napier, Breal, Konrath, Schick u. a. sind schuler von Zupitza, von schtlern von ten Brink ist ausser dem unterzeichneten wol keiner an einer hochschule tätig. Aber gerade durch ihre verschiedenheiten ergänzten sich die 
beiden hochverdienten gelehrten: ohne ihre beiderseitigen arbeit hätte sich die englische philologie nicht so rasch zu ihrer jetzigen blute entfaltet und alle, die sich mit diesen studien beschäftigen, werden ihnen daher ein dankbares andenken bewahren.

Zupitzas lebensgang war ein ziemlich ruhiger. Rasch, in sieben jahren, stieg er vom privatdocenten in Breslan bis zum ordentlichen professor in Berlin. Am 4. Januar 1844 auf einem gute in Kerpen bei Ober-Glogan in Schlesien geboren, besuchte er, auf seiner dorfschule vorgebildet, das gymnasium zu Oppeln, das er herbst 1862 verliess. Er studierte alsdann drei semester in Breslau und vier in Berlin unter Haupt and Mullenhoff alte sprachen und germanistik, auch mit romanistik beschäftigte er sich. Hier wurde er 1865 anf die arbeit: 'Prolegomena Alberti de Kemenaten Eckium' hin promoviert. 1869 habilitierte er sich mit einer abhandlung 'Verbesserungen zu den Drachenkämpfen' in Breslau, nachdem er in Oppeln sein probejahr am gymnasium abgeleistet und hilfslehrer am Matthiasgymnasium in Breslan geworden war. Seine Venia docendi umfasste nicht nur Gothisch und Deutsch, auch Nordisch und Englisch, sogar uber Romanisch las er. Durch diese vielseitigkeit zog er den blick auf sich, als man in Wien eine nengegrtindete professur fur 'Nordgermanisch' (d. h. fur Englisch und Nordisch) besetren wollte. Oktober 1872 trat er seine ausserordentliche professur in Wien an, die bald in ein ordinariat verwandelt wurde. 1876 wurde er als ordinarius fur englische philologie nach Berlin berufen und in dieser stellung blieb er bis zu seinem tod. Zupitza starb sehr plötzlich durch einen gehiruschlag am frthen morgen des 6 . Juli.

Von selbständigen schriften, soweit sie auf englischem gebiet sich bewegen, sind za nennen:

1873. Zur Literaturgeschichte des Gay von Warwick. Wien.

1874. Altenglisches Uebungsbuch zum Gebrauche bei Universitätsvorlesungen. Mit einem Worterbuche. Wien. 2. Aufl. 1882. 3. Aufl. 1884. 4. Aufl. 1889.

1876. The Romance of Guy of Warwick. Second or $15^{\text {th }}$ Century Version. London.

1877. Cynewulf's Elene. Mit einem Glossar. Berlin. 2. Anf. 1883. 3. Aufl. 1888. 
1878. Fr. Koch's Satzlehre der englischen Sprache. 2. Aufl. besorgt von Zupitza. Kassel.

1880. Varianten zu Chaucer, ed. by Morris. Als Manuscript gedruckt. Berlin.

1881. Alfric's Grammatik u. Glossar. 1. Abt.: Text u. Varianten. Berlin.

1882. Chancer. The Book of the Tales of Cannterbury: Prolog. Mit Varianten. Zum Gebrauch bei Vorlesungen. Berlin. Sttucke aus den altenglischen Evangelien. Als Ms. fur Vorlesungen gedruckt. Berlin.

Beownlf. Autotypes of the Ms. With Transliteration and Notes. London.

Fr. Koch's Laut- und Flexionslehre der engl. Sprache. 2. Aufl. besorgt von Zupitza. Kassel.

1883. Romance of Guy of Warwick. Ed. from the Auchinleck Ms., and from the Ms. in Cains Coll. London.

1888. The Romance of Gay of Warwick. Part II. London. 1891. The Romance of Gay of Warwick. Part III. London. 1892. Specimens of all the accessible unprinted Mss. of the Canterbury Tales. London.

Ausser diesen werken finden sich aufsätze in der 'Zeitschrift fur deutsches Altertum', in der 'Anglia', den 'Englischen Studien' und dem 'Archiv fur neuere Sprachen' und Anzeigen im 'Anzeiger der Zeitschr. f. d. A.', in der 'Literaturzeitung', der 'Zeitschrift fur österr. Gymnasien' und ganz besonders reichlich in dem 'Archiv fur neuere Sprachen', das Zupitza seit 1890 (Bd. 84) bis zu seinem tode redigierte.

LEIPZiG-GoHLis.

RICHARD WÜLKER. 